\title{
Полупроводниковые вертикально-излучающие лазеры для компактных атомных сенсоров
}

\author{
В.М. Устинов ${ }^{1,2)}$, Н.А. Малеев ${ }^{2)}$, С.А. Блохин ${ }^{2)}$ \\ ${ }^{1}$ НТЦ Микроэлектроники РАН, Санкт-Петербург, \\ 194021, Политехническая, 26 \\ ${ }^{2}$ Физико-технический институт им. А.Ф.Иоффе, Санкт-Петербург, \\ 194021, Политехническая, 26 \\ тел:+7 (812) 297-4059, факс: +7 (812) 297-4059, эл.nочта: vmust@ beam.ioffe.ru
}

DOI 10.34077/RCSP2019-78

В последние годы компактные атомные сенсоры (компактные атомные часы, гироскопы на ядерном магнитном резонансе, миниатюрные магнетометры) являются предметом большого количества исследований, в том числе в связи с возможностью из применения в компактных системах навигации. В данных устройствах используются эффекты взаимодействия оптического излучения с тонкой структурой энергетических уровней в атомах газов щелочных металлов (рубидия или цезия) [1]. При этом в качестве источников излучения используются компактные полупроводниковые вертикально-излучающие лазеры, к параметрам которых предъявляются жесткие требования. Например, при использовании в компактных атомных часах кроме точного попадания в требуемую спектральную линию (например, $\mathrm{D}_{1} 133$ изотопа цезия (894.3 нм), излучение такого лазера должно быть одномодовым с коэффициентом подавления боковых мод более 20 дБ, линейно поляризованным с коэффициентом подавления ортогональной поляризации более 15 дБ, иметь ширину линии менее 100 МГц, ширина полосы частот эффективной модуляции лазера должна превышать 5 ГГц, а типичный диапазон рабочих температур составляет 60 - 90 $\mathrm{C}$.

В настоящей работе для создания вертикально-излучающих лазеров использовалась структура с нелегированными распределенными брэгговскими отражателями, внутрирезонаторными контактами и активной областью на основе InGaAs квантовых ям, выращенная методом молекулярно-пучковой эпитаксии. Стабилизация направления поляризации излучения, показанная на рис.1, обеспечивалась ромбовидной формой токовой апертурой, получаемой при селективном окислением в парах воды слоя AlGaAs специальной конструкции [2].

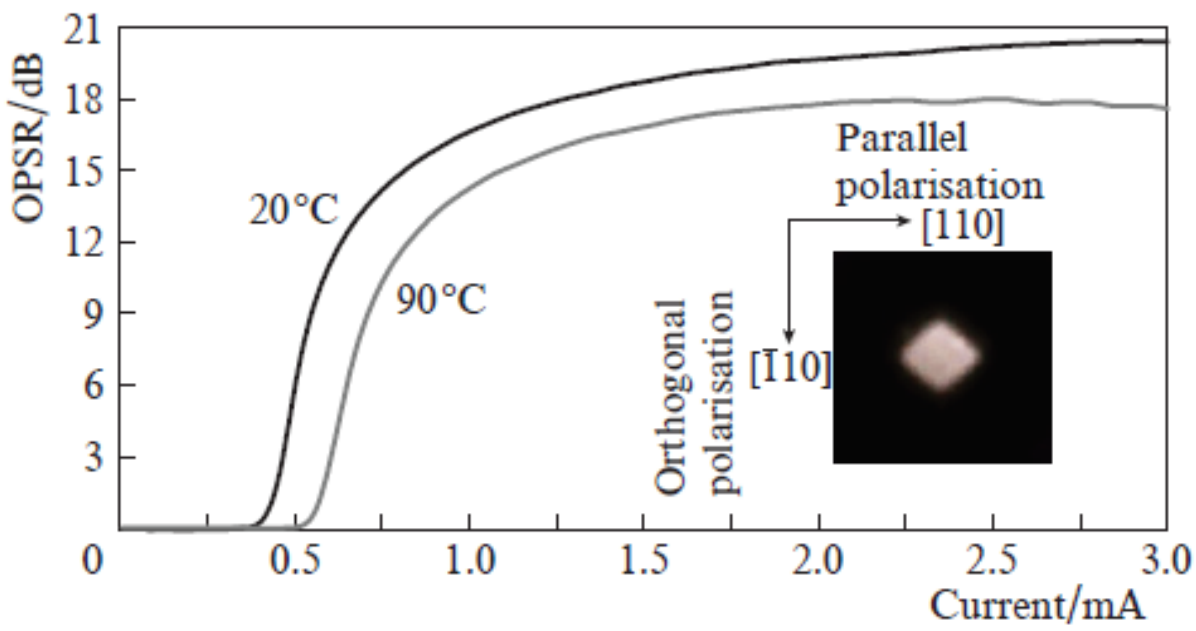

Рис. 1. Зависимость коэффициента подавления ортогональной поляризации от тока накачки. На вставке - картина ближнего поля излучения лазера в предпороговом режиме.

Созданные лазеры демонстрируют высокую выходную мощность в одномодовом режиме с фиксированной поляризацией (более $1 \mathrm{мBT),} \mathrm{пороговый} \mathrm{ток} \mathrm{менее} 1 \mathrm{~mA}$, эффективную частоту модуляции более 5 ГГц и ширину линии излучения менее 60 МГц при температурах $65-75^{\circ}$. Достигнутые характеристики обеспечивают возможность эффективного применения разработанных лазеров в компактных атомных сенсорах.

\section{Лumepamypa}

[1] Kitching J. Appl. Phys. Rev., 5 (3), 031302 (2018)

[2] D.E. Nazaruk, et al, J. Phys.: Conf. Ser., v. 572, 1 ArtNo: \#012036 (2014) 